\title{
MODAL-COTTON FIBRE BLEND RATIO AND RING FRAME PARAMETER OPTIMISATION THROUGH THE TAGUCHI METHOD
}

\author{
Maheswaran R \& Srinivasan V
}

Department of Mechanical Engineering, Mepco Schlenk Engineering College, Sivakasi-626005, Tamil Nadu, India, Department of Textile Technology, P.A.C. Ramasamy Raja Polytechnic College, Rajapalayam-626108, Tamil Nadu, India, Tel:0091-9443455876, Email: srinivasan@pacrpoly.org

\section{Abstract:}

The influence of Modal-cotton (MC) fibre blend ratio and ring frame machine parameters such as front top roller loading and break draft on the blended yarn properties has been studied. Compact MC blended yarn samples of 14.75 tex with three different MC fibre blend ratio has been produced in a LR 6 ring spinning frame fitted with Suessen Compact drafting system. A robust design optimisation to minimise the variations of the output yarn properties such as blended yarn tenacity, yarn unevenness and hairiness caused because of the variations in the material as well as machine setting parameters is achieved through the Taguchi parametric design approach. It is found that the maximum compact MC blended yarn tenacity is $23.76 \mathrm{~g} / \mathrm{tex}$, which is influenced very much by MC fibre blend ratio but meagrely by top roller loading and break draft. Similarly, the minimum 9.54 U\% and 3.59 hairiness index are achieved with 100:0 and 70:30 MC fibre blend ratio, respectively, at 23-kg top roller loading. Statistical ANOVA analysis is performed on the results and optimum values are obtained within the $95 \%$ confidential level through confirmation experiments.

\section{Keywords:}

Break draft, Blended yarn, Modal-cotton fibre blend ratio, Robust design, Taguchi method, Top roller loading

\section{Introduction}

In the textile industry, ring spinning is an important process involved to produce spun yarns of various qualities required for different applications from different natural or synthetic or regenerated fibres [1]. Blending of different types of fibres is practiced to enhance the quality characteristics of yarn by incorporating desirable properties of constituent fibres and to reduce the cost [2]. Fibre blend ratio is an important factor that determines the properties of spun yarn and is specified by the types of fibres and their ratio in the resultant mixture [3-5]. Modal fibre, a regenerated viscose fibre having better characteristics such as strength, moisture absorption, length uniformity, shrinkage, softness and appearance, is found to be compatible to blend with natural cotton fibre in different blend ratio to produce modal-cotton (MC) blended yarn. Modal yarn and MC blended yarn can be used to manufacture knitted fabric with desirable characteristics for various applications such as bed linen, sports and casual and inner wears [6]. Several works are reported on comparison of quality characteristics of yarn and knitted fabrics made from $100 \%$ modal yarn and $100 \%$ cotton yarn $[6,7]$. But little work is found with regard to MC blended yarn and fabric. Different ratio of modal and cotton fibres are blended in the draw frame and reduced to a composite roving, and it is converted as a blended ring yarn in a ring spinning frame. Furthermore, the properties of the blended ring yarn also depend on the ring spinning process parameters such as spindle speed, top roller pressure and diameter, traveller mass, break draft, twist factor and shore hardness of cots [8].

Ishtiaque et al. [9] reported that spinning machine parameters such as spindle speed, top roller pressure and traveller mass are influencing the ring yarn qualities such as strength, unevenness and hairiness significantly. Ghane et al. [10] have studied and observed that the top roller diameter significantly affects the unevenness of ring spun polyester/cotton blended yarn quality. Khalilur Rahman Khan et al. [11] investigated the effect of spindle speed and twist on the strength, unevenness and elongation quality of viscose/melange cotton blended spun yarn with different blend ratio. Arindam Basu et al. [12] proved that spindle speed, break draft and spacer size are influencing the imperfections and unevenness properties of polyester/ cotton blend yarn. Mohammad Hatamvand et al. [13] reported that the effect of total draft, break draft and roller pressure on the properties of ring spun polyester/viscose blend yarns is significant.

Blended yarn qualities such as tenacity, unevenness and hairiness highly depend on the fibre-material-dependent parameters such as blend ratio of fibres and the ring frame spinning machine setting parameters such as top roller load pressure, break draft and spindle speed. Among these machine setting parameters, top roller loading pressure of ring frame controls the movement of the fibres because of fibre slip between the drafting rollers. An optimum top roller loading machine setting helps to move the fibres in the drafting rollers and effectively controls the erratic movement of floating fibres with less fibre slippage. With the increase in top roller loading pressure setting, the yarn tenacity may increase initially up to certain level and tend to decrease because of less freedom for fibre movement. Similarly, blended yarn unevenness and hairiness shows an initial decrease with the increase in the top roller load pressure. Furthermore, break draft setting in the ring spinning frame removes the mild twist present in the roving 
and the higher break draft may increase the fibre breakage at the back zone. An optimum break draft setting leads to a better consolidation and preparation of fibre strand just before it is drafted in main zone. Break draft setting higher than the optimum causes reduction in the yarn tenacity and increase in the $U$-percentage and hairiness index of yarn. Furthermore, an economic justification of the blend ratio of modal/cotton fibres is also to be considered because of the higher modal fibre cost.

Owing to high complexity of spinning process, implementation of robust design in manufacturing good-quality blended yarn as per customer satisfaction gained much importance [14]. The Taguchi method is one of the important tools used in robust design that focuses on the effective application of engineering strategies rather than advanced statistical techniques [15]. It helps to reduce variability in a product or process by simultaneously guiding input variations towards an optimal setting. Few studies have been reported on the application of the Taguchi design in textile field to optimise and predict the yarn and fabric properties. Akshay Kumar et al. [16] examined how the ring, rotor and air-jet yarn packing parameters are influenced by the lap hank, card draft, draft in simplex, ring frame, rotor machine and in air-jet system using the Taguchi design. Akshay Kumar et al. [17,18] reported the impact of various process parameters in spinning preparatory and in spinning on several properties of ring, rotor and air-jet yarn using the Taguchi method and analysis of variance (ANOVA). Serin mavruz and Tangrul [19] proved that the Taguchi design can be used to determine the influencing parameters on maximising the bursting strength of knitted fabrics. Tanveer Hussain et al. [20] simplified the optimisation of multiple performance characteristics of cotton rotor yarn through the Taguchi method. Anindya Ghosh et al. [21] used the Taguchi method to investigate the influence of yarn and knitting machine parameters on comfort properties of knitted fabric.

Among the three phases of the Taguchi design, namely, system design, parameter design and tolerance design, this study is focussed on the parameter design of optimising the various quality characteristics of yarn through systematic approach for quality improvement quickly without incurring much additional cost. The aim of this investigation is the simultaneous parameter optimisation of material parameter such as blend ratio of fibre and also ring spinning process parameters such as top roller loading and break draft towards the yarn quality characteristics such as maximising the strength of the modal-cotton blended yarn and minimising its hairiness and unevenness.

\section{Experimental}

The modal and cotton fibres mixed in three different ratios were used in this work towards the design and development of highquality blended yarn. Furthermore, controllable factors in ring spinning process such as top roller loading and break draft affecting the output performance of blended yarn were selected in three different levels to produce blended yarn samples. The variations caused in the output performance of blended yarn such as tenacity, unevenness and hairiness because of the above factors were evaluated.

\subsection{Materials and Methods}

The basic characteristics such as $2.5 \%$ span length, uniformity index, fineness and bundle strength of cotton fibres selected for this work are $31 \mathrm{~mm}, 82.71,4.36 \mu \mathrm{g} / \mathrm{inch}$ (1.5 den) and $32.15 \mathrm{~g} /$ tex, respectively. The corresponding characteristics of chosen pro-Modal fibres are $38 \mathrm{~mm}, 100,1.3$ denier and $36 \mathrm{~g} /$ tex, respectively.

The MC blended yarn was prepared in compact ring spinning process. Here natural cotton fibres and modal fibres were processed separately in spinning preparatory machines to produce slivers. Then the combed cotton slivers and modal draw frame slivers (LRDO/2S) were blended in various blend ratios in finisher draw frame (RSB851) to produce MC composite slivers. The above draw frame blending was done according to the individual number of slivers and its weight per unit length. The weight/unit length of composite sliver and the blend ratio are calculated by using the formula

Weight/unit length of composite sliver

$\left(\mathrm{W}_{\mathrm{mc}}\right)=\left(\mathrm{N}_{\mathrm{m}} \times \mathrm{W}_{\mathrm{m}}+\mathrm{N}_{\mathrm{c}} \times \mathrm{W}_{\mathrm{c}}\right) / \mathrm{D}$

where $\mathrm{Nm}$ is the number of modal slivers, $\mathrm{Wm}$ is the weight/ unit length of modal sliver, $\mathrm{Nc}$ is the number of cotton slivers, Wc is the weight/unit length of cotton sliver and $D$ is the draw frame draft.

A suitable composite roving was produced as per weight/unit length of composite sliver by processing in a simplex machine (LR GS). This composite roving was feed into a ring frame (LR 6 fitted with Suessen Compact HPA 320 drafting system) that produced the compact blended yarn of 14.75 tex with 3.58 TM. Schematic representation of the ring spinning process for the production of MC blended yarn is given in Figure 1.

The tenacity of MC blended yarn was measured using the Uster Tenso Rapid 3 (UTR 3) at a cross head speed of $50 \mathrm{~m} / \mathrm{min}$. The unevenness (U\%) and hairiness (hairiness index) were tested using Uster Evenness tester (UT3) at a cross head speed of $400 \mathrm{~m} / \mathrm{min}$. The performance of a yarn was calculated as an average of 10 samples measured using the above equipments.

\subsection{Robust Design - Taquchi method}

The Taguchi method is used to build quality into the product during the design stage. Here for the design and development of high-quality MC blended yarn, the Taguchi parameter design method has been applied to find the optimum level of selected parameters for producing good-quality material with minimum time and less cost. This method is focussed on performing some minimum number of experiments instead of full factorial number of experiments, to test the variations caused in a set of response variables to a set of control parameters by finding the optimum setting value of the control parameters [15]. Two major techniques used in the Taguchi method are the orthogonal array (OA), which decides the number of experiments needs to be conducted, and the signal-to-noise ratio (SNR or S/N ratio), which summarises the output performance criterion [15]. 


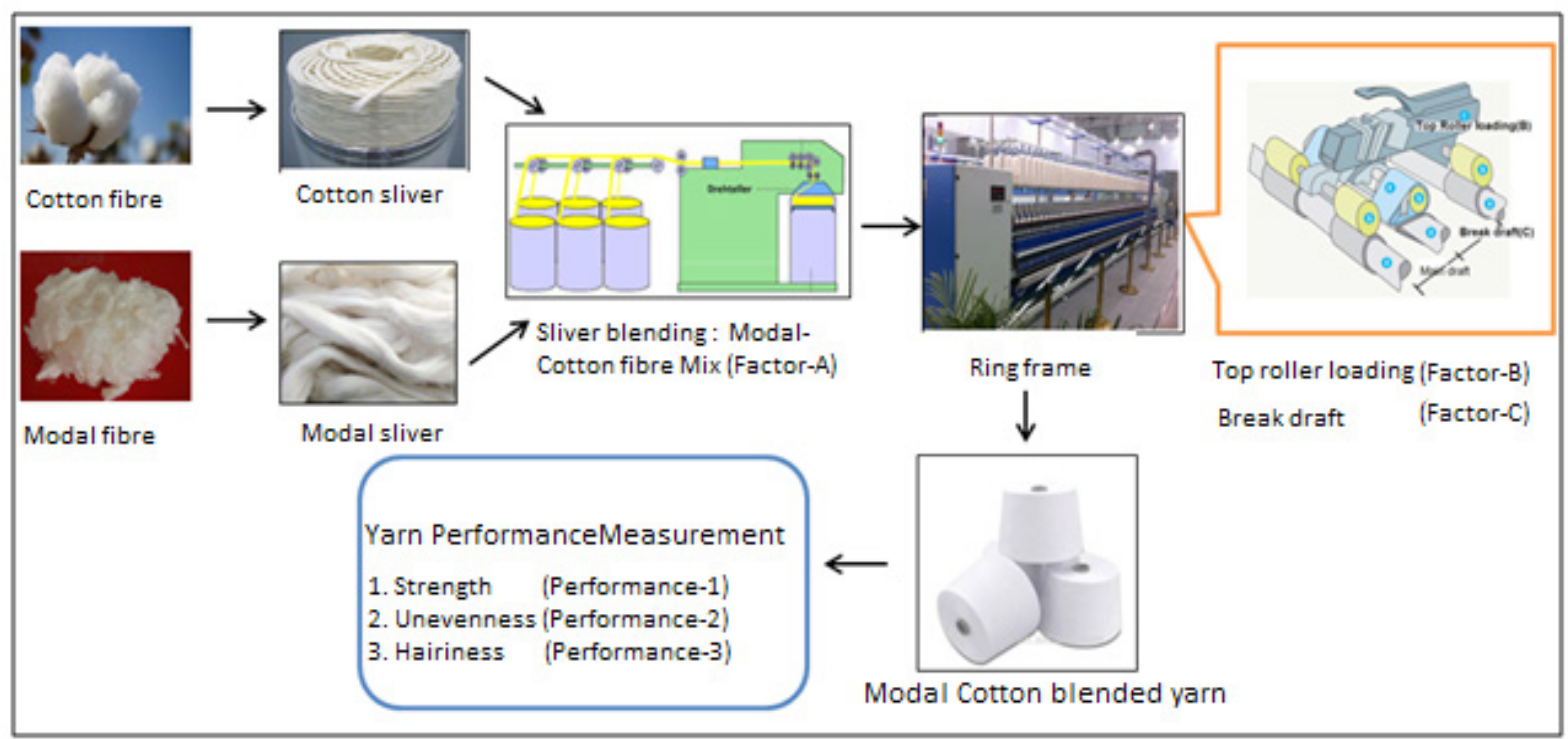

Figure 1. Modal-cotton blended yarn preparation in ring spinning process

According to the Taguchi parametric design, the functional characteristics of any product is affected by two types of factors, namely, control factors and noise factors. Control factors such as material choice, speed, top roller loading of spinning machine and break draft can easily be controlled, and factors that are difficult or too expensive to control are termed as noise factors. The levels of each control factors and noise factors to be tested can be predetermined to suit the orthogonal arrays. In this study, the blend ratio, top roller loading and break draft setting were taken as input control factors for the proposed robust design of the Taguchi method. In this analysis, MC blend ratio proportion was considered as Factor $A$ and top roller loading and break draft were considered as Factor B and Factor C, respectively, and these are depicted in Figure 1. The levels of control factors are selected based on the practical conditions in spinning industries.

The Taguchi method recommends OA to systematically vary and test the various levels of each of the control factors based on generalised Graeco-Latin squares. Any standard OA can be selected from the available list based on the factors and their levels. Standard L9 orthogonal was used for 3 factors at 3 different levels for this proposed study.

The output performance values or response values were obtained from the experimental results by calculating the $\mathrm{S} / \mathrm{N}$ ratio. The $\mathrm{S} / \mathrm{N}$ ratio $(\eta)$ is the ratio of sensitivity of the performance to the variability of the input factors involved. The higher $\mathrm{S} / \mathrm{N}$ ratio value shows the better quality of the product. The method used for calculating $\mathrm{S} / \mathrm{N}$ ratio is different for three different categories of quality characteristics [15], which are given in equations 2 to 4 .

Lower is better

$$
\frac{\mathrm{S}}{\mathrm{N}}=-10 \log \left[1 / \mathrm{n} \sum_{\mathrm{i}=1}^{\mathrm{n}} \mathrm{yi}^{2}\right]
$$

Higher is better

$$
\frac{\mathrm{S}}{\mathrm{N}}=-10 \log \left[1 / \mathrm{n} \sum_{\mathrm{i}=1}^{\mathrm{n}} 1 / \mathrm{yi}^{2}\right]
$$

$\mathrm{n}$ is the number of experiments and $\mathrm{y}_{\mathrm{i}}$ is the ith value measured.

Nominal is best

$$
\frac{\mathrm{s}}{\mathrm{N}}=-10 \log \left[\mathrm{y}^{2} / \mathrm{s}^{2}\right]
$$

$\mathrm{y}^{2}$ is the average of the observed data and $\mathrm{s}^{2}$ is the variation.

The method of calculating the $\mathrm{S} / \mathrm{N}$ ratio in Taguchi method depends on whether the quality characteristic is lower-thebetter like minimum yarn hairiness and unevenness of blended yarn or larger-the-better like maximum yarn strength, elongation and so on or nominal-the-best like twist of yarn. Here S/N ratio for yarn hairiness $(\mathrm{H})$ and unevenness $(\mathrm{U} \%)$ was calculated using equation 2 and for yarn tenacity $(\mathrm{T})$ was calculated using equation 3 .

Agraphical plot (main effect plot) was drawn to find the optimum level for each factor, in which average effects were plotted for each factor against its corresponding levels. Factor level that best maximises average $\mathrm{S} / \mathrm{N}$ effect was chosen as optimum level from graphical plot. Also a response table was prepared for determining the significant effect of each factor on the yarn quality characteristics.

In order to identify the factors that have significant influence on the final test results, ANOVA for $S / N$ ratio values was performed. This analysis was performed using MTAB7 statistical software. Furthermore, the value of the multiple $\mathrm{S} / \mathrm{N}$ ratios at the optimum level was predicted using equation 5 . This predicted value was used for verification with actual value obtained at optimal settings for realisation.

$$
\eta_{0}=\eta_{\mathrm{m}}+\sum_{\mathrm{i}=1}^{\mathrm{j}}\left(\eta_{\mathrm{i}}-\eta_{\mathrm{m}}\right)
$$


$\eta_{0}$ is the predicted optimum S/N ratio, $\eta_{m}$ is the mean values of multiple $S / N$ ratios in all experiments, $\eta_{i}$ is the multiple $S / N$ ratio corresponding to optimum factor levels and $\mathrm{J}$ is the number of factors

Also confirmation experiment using optimum settings of the factors and levels that were determined already was performed for verification. Finally, closeness of the experimental values and predicted values was evaluated by performing statistical analysis.

\section{Results and Discussion}

MC blended compact yarn samples were produced with different MC\% composition such as $50: 50,70: 30$ and $100: 0$ by varying machine parameters, namely, top roller loading and break draft in ring frame. The cross-sectional (CS) SEM (scanning electron microscopic) image of the three yarn samples with different $\mathrm{MC} \%$ are given in Figure 2. Zeiss sigma V-Scanning Electron Microscope at SITRA, Coimbatore, was used to obtain the CS images of our samples. Figure 2(d) shows the CS image of single modal and cotton fibres. The yarn performance characteristics, namely, tenacity $(\mathrm{T})$, unevenness $\%(\mathrm{U})$ and hairiness index $(H)$, were measured for all the samples by conducting 10 similar tests. From the test results, the effect of $\mathrm{MC}$ fibre blend ratio on yarn performance was studied. Furthermore, the interaction between the ring spinning frame parameters and blended yarn performance were analysed. Finally, a robust design optimisation was performed through the Taguchi method.

\subsection{Effect of blend ratio on yarn performance}

Test results of tenacity, unevenness and hairiness index for MC blended yarn samples spun with three different MC blend ratio compositions at constant ring frame parameters such as top roller loading of $18 \mathrm{~kg}$ and break draft of 1.18 are reported in Table 1. Furthermore, the interaction of yarn tenacity, unevenness and hairiness index against MC\% are illustrated in Figure 3.

\subsubsection{Tenacity}

It can be observed from Figure 3(a) that as the percentage of modal fibre increases in the blend ratio, the average values of tenacity of MC blended yarn increases. This trend is due to the fact that the strength, length and length uniformity of fibres, which contributes directly towards yarn strength, are better in modal fibres than cotton fibres. Moreover, the number of finer modal fibres in blended yarn CS may increase as the proportion of modal fibre increases in the blend ratio and may lead to tenacity improvement.

\subsubsection{Unevenness}

Figure $3(b)$ reveals that as the percentage of modal fibre increases in the blend ratio, the average values of unevenness of MC blend yarn decreases. This trend is contributed by the higher length uniformity and the absence of short fibres in the modal fibres compared to cotton fibres. Short fibre content, which creates more floating fibres in the drafting system, is not present in modal fibre mix, and this leads to lower yarn $U \%$.

\subsubsection{Hairiness Index}

Figure 3(c) clearly shows that as the percentage of modal fibre increases in the blend ratio, the average values of hairiness index of MC blended yarn decreases. This is due to the fact that the length and length uniformity index of the modal fibres is higher than cotton mix. This trend is observed up to MC 70:30 blend. But in $100 \%$ modal yarn, the fibres are finer and, hence, more number of fibres is accommodated in yarn CS. More fibre will lead to more fibre ends and, hence, increased yarn hairiness.

\subsection{Effect of interaction of ring spinning machine parameters}

A box plot displays variations in a set of data along with mean and median and allows multiple set of data to be displayed on the same graph, which is easy to analyse. The interaction of ring frame machine parameters such as top roller loading and

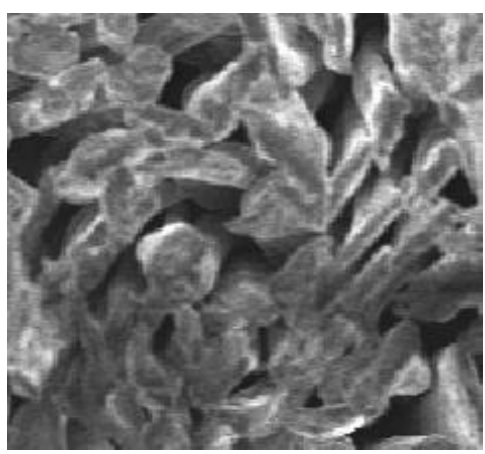

(a)

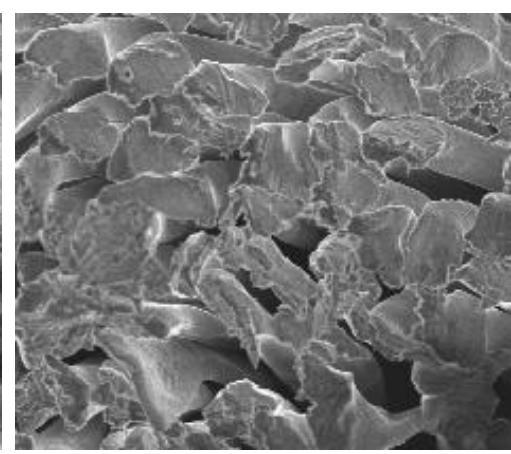

(b)
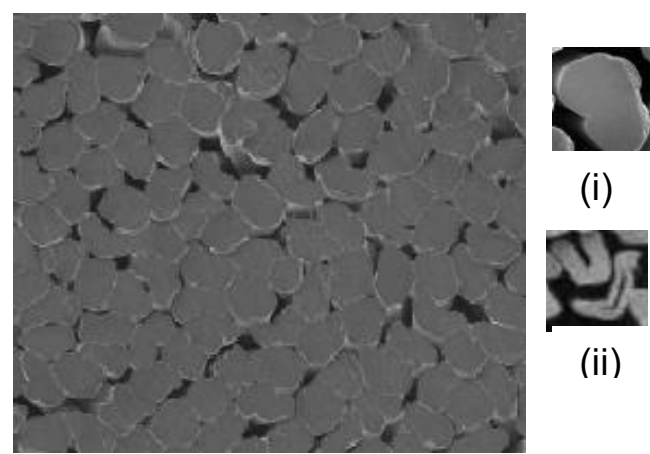

(i)

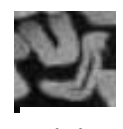

(ii)

(c) (d)

Figure 2. SEM CS image of MC blended yarn: (a) $M C \%=50: 50$, (b) $M C \%=70: 30$, (c) $M C \%=100: 0$, (d-i) modal fibre image and (d-ii) cotton fibre image 
Table 1. Tenacity, $U \%$ and hairiness index of MC blended yarn

Table A

\begin{tabular}{|c|c|c|c|c|c|c|c|c|c|}
\hline \multirow{2}{*}{ Test No. } & \multicolumn{3}{|c|}{ Tenacity (g/tex) } & \multicolumn{3}{c|}{ Unevenness (\%) } & \multicolumn{3}{c|}{ Hairiness index } \\
\cline { 2 - 10 } & $\begin{array}{c}\text { M:C\%- } \\
\mathbf{5 0 : 5 0}\end{array}$ & $\begin{array}{c}\text { M:C\%- } \\
\mathbf{7 0 : 3 0}\end{array}$ & $\begin{array}{c}\text { M:C\%- } \\
\mathbf{1 0 0 : 0}\end{array}$ & $\begin{array}{c}\text { M:C\%- } \\
\mathbf{5 0 : 5 0}\end{array}$ & $\begin{array}{c}\text { M:C\%- } \\
\mathbf{7 0 : 3 0}\end{array}$ & $\begin{array}{c}\text { M:C\%- } \\
\mathbf{1 0 0 : 0}\end{array}$ & $\begin{array}{c}\text { M:C\%- } \\
\mathbf{5 0 : 5 0}\end{array}$ & $\begin{array}{c}\text { M:C\%- } \\
\mathbf{7 0 : 3 0}\end{array}$ & $\begin{array}{c}\text { M:C\%- } \\
\mathbf{1 0 0 : 0}\end{array}$ \\
\hline $\mathbf{1}$ & 16.62 & 19.37 & 22.64 & 9.66 & 9.94 & 9.64 & 5.49 & 4.54 & 4.16 \\
\hline $\mathbf{2}$ & 16.58 & 19.27 & 23.43 & 9.61 & 9.72 & 9.66 & 5.53 & 4.50 & 4.39 \\
\hline $\mathbf{3}$ & 16.83 & 19.35 & 23.03 & 9.78 & 9.66 & 10.0 & 5.23 & 4.64 & 4.29 \\
\hline $\mathbf{4}$ & 16.04 & 18.95 & 22.36 & 9.75 & 9.52 & 9.79 & 5.33 & 5.06 & 3.68 \\
\hline $\mathbf{5}$ & 17.28 & 18.71 & 24.28 & 9.93 & 9.77 & 9.59 & 5.14 & 4.93 & 3.92 \\
\hline $\mathbf{6}$ & 17.64 & 18.45 & 22.14 & 9.61 & 10.20 & 9.67 & 5.36 & 4.47 & 4.28 \\
\hline $\mathbf{7}$ & 16.54 & 19.25 & 23.85 & 9.74 & 9.70 & 10.13 & 5.29 & 4.52 & 4.31 \\
\hline $\mathbf{8}$ & 17.10 & 18.92 & 22.57 & 10.24 & 9.53 & 9.79 & 5.49 & 4.90 & 3.64 \\
\hline $\mathbf{9}$ & 16.68 & 19.52 & 22.64 & 9.88 & 9.82 & 9.68 & 5.27 & 4.78 & 3.89 \\
\hline $\mathbf{1 0}$ & 16.89 & 18.51 & 22.79 & 10.11 & 9.95 & 9.53 & 5.18 & 4.59 & 3.85 \\
\hline Average & 16.82 & 19.03 & 22.97 & 9.84 & 9.78 & 9.75 & 5.33 & 4.69 & 4.04 \\
\hline SD & 0.44 & 0.38 & 0.68 & 0.21 & 0.21 & 0.19 & 0.14 & 0.21 & 0.28 \\
\hline
\end{tabular}

Table B

\begin{tabular}{|c|c|c|c|c|c|c|c|c|c|}
\hline \multirow{2}{*}{ Test No. } & \multicolumn{3}{|c|}{ Tenacity (g/tex) } & \multicolumn{3}{c|}{ Unevenness (\%) } & \multicolumn{3}{c|}{ Hairiness index } \\
\cline { 2 - 10 } & $\begin{array}{c}\text { M:C\%- } \\
\mathbf{5 0 : 5 0}\end{array}$ & $\begin{array}{c}\text { M:C\%- } \\
\mathbf{7 0 : 3 0}\end{array}$ & $\begin{array}{c}\text { M:C\%- } \\
\mathbf{1 0 0 : 0}\end{array}$ & $\begin{array}{c}\text { M:C\%- } \\
\mathbf{5 0 : 5 0}\end{array}$ & $\begin{array}{c}\text { M:C\%- } \\
\mathbf{7 0 : 3 0}\end{array}$ & $\begin{array}{c}\text { M:C\%- } \\
\mathbf{1 0 0 : 0}\end{array}$ & $\begin{array}{c}\text { M:C\%- } \\
\mathbf{5 0 : 5 0}\end{array}$ & $\begin{array}{c}\text { M:C\%- } \\
\mathbf{7 0 : 3 0}\end{array}$ & $\begin{array}{c}\text { M:C\%- } \\
\mathbf{1 0 0 : 0}\end{array}$ \\
\hline $\mathbf{1}$ & 16.62 & 19.37 & 22.64 & 9.66 & 9.94 & 9.64 & 4.54 & 4.16 & 5.49 \\
\hline $\mathbf{2}$ & 16.58 & 19.27 & 23.43 & 9.61 & 9.72 & 9.66 & 4.50 & 4.39 & 5.53 \\
\hline $\mathbf{3}$ & 16.83 & 19.35 & 23.03 & 9.78 & 9.66 & 10.0 & 4.64 & 4.29 & 5.23 \\
\hline $\mathbf{4}$ & 16.04 & 18.95 & 22.36 & 9.75 & 9.52 & 9.79 & 5.06 & 3.68 & 5.33 \\
\hline $\mathbf{5}$ & 17.28 & 18.71 & 24.28 & 9.93 & 9.77 & 9.59 & 4.93 & 3.92 & 5.14 \\
\hline $\mathbf{6}$ & 17.64 & 18.45 & 22.14 & 9.61 & 10.20 & 9.67 & 4.47 & 4.28 & 5.36 \\
\hline $\mathbf{7}$ & 16.54 & 19.25 & 23.85 & 9.74 & 9.70 & 10.13 & 4.52 & 4.31 & 5.29 \\
\hline $\mathbf{8}$ & 17.10 & 18.92 & 22.57 & 10.24 & 9.53 & 9.79 & 4.90 & 3.64 & 5.49 \\
\hline $\mathbf{9}$ & 16.68 & 19.52 & 22.64 & 9.88 & 9.82 & 9.68 & 4.78 & 3.89 & 5.27 \\
\hline $\mathbf{1 0}$ & 16.89 & 18.51 & 22.79 & 10.11 & 9.95 & 9.53 & 4.59 & 3.85 & 5.18 \\
\hline Average & 16.82 & 19.03 & 22.97 & 9.84 & 9.78 & 9.75 & 4.69 & 4.04 & 5.33 \\
\hline SD & 0.44 & 0.38 & 0.68 & 0.21 & 0.21 & 0.19 & 0.21 & 0.28 & 0.14 \\
\hline
\end{tabular}

Note: In table A, Hairiness Index values of M:C\%-50:50, M:C\%-70:30, M:C\%-100:0 are wrongly entered. It is corrected in Table $B$.

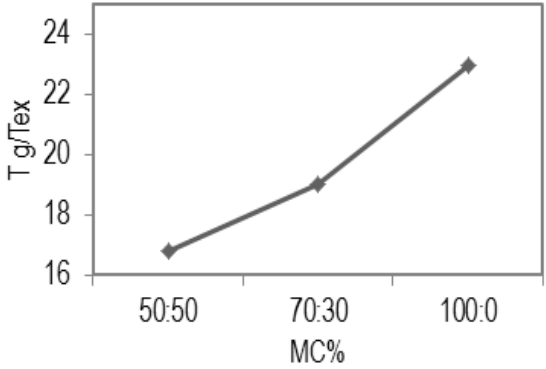

(a)

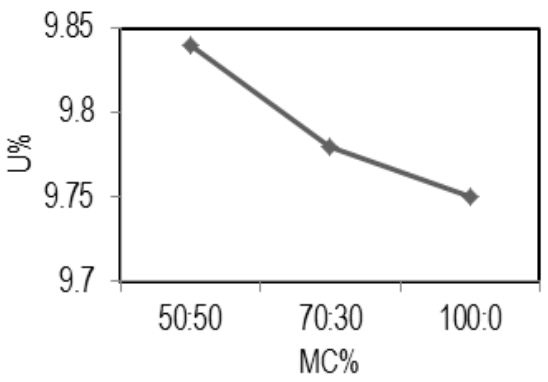

(b)

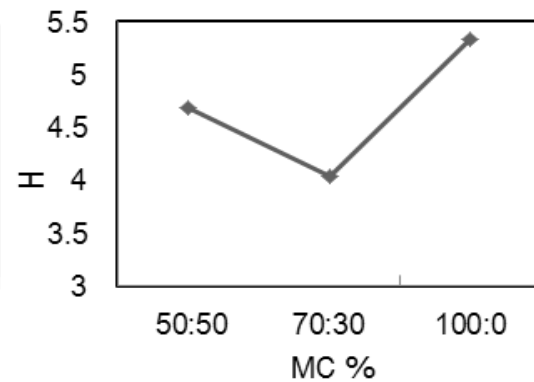

(c)

Figure 3. Effects of MC\% on blended yarn (a) tenacity, (b) unevenness and (c) hairiness index 
break draft on MC blended yarn properties such as tenacity, unevenness and hairiness index illustrated using box plots is shown in Figures 4 and 5.

\subsubsection{Tenacity $(T)$}

It is observed from Figure 4 that as the top roller loading increases, the blended yarn tenacity increases to some extent irrespective of the blend ratio. This is due to the better control of both modal and cotton fibres and less fibre slippage in the drafting system at the higher top roller loading. The yarn tenacity increases initially and then decreases as the BD value increases. Modal fibres are consolidated and prepared well in the back zone at the medium break draft levels. It is found that the maximum $\mathrm{T}$ for the $\mathrm{MC}$ blended yarn is obtained at a top roller loading of $23 \mathrm{~kg}$. The BD value of 1.18 gives maximum tenacity for all the samples except for 50:50 MC blended yarn at $20-\mathrm{kg} \mathrm{TL}$, which gives better value at $1.13 \mathrm{BD}$.

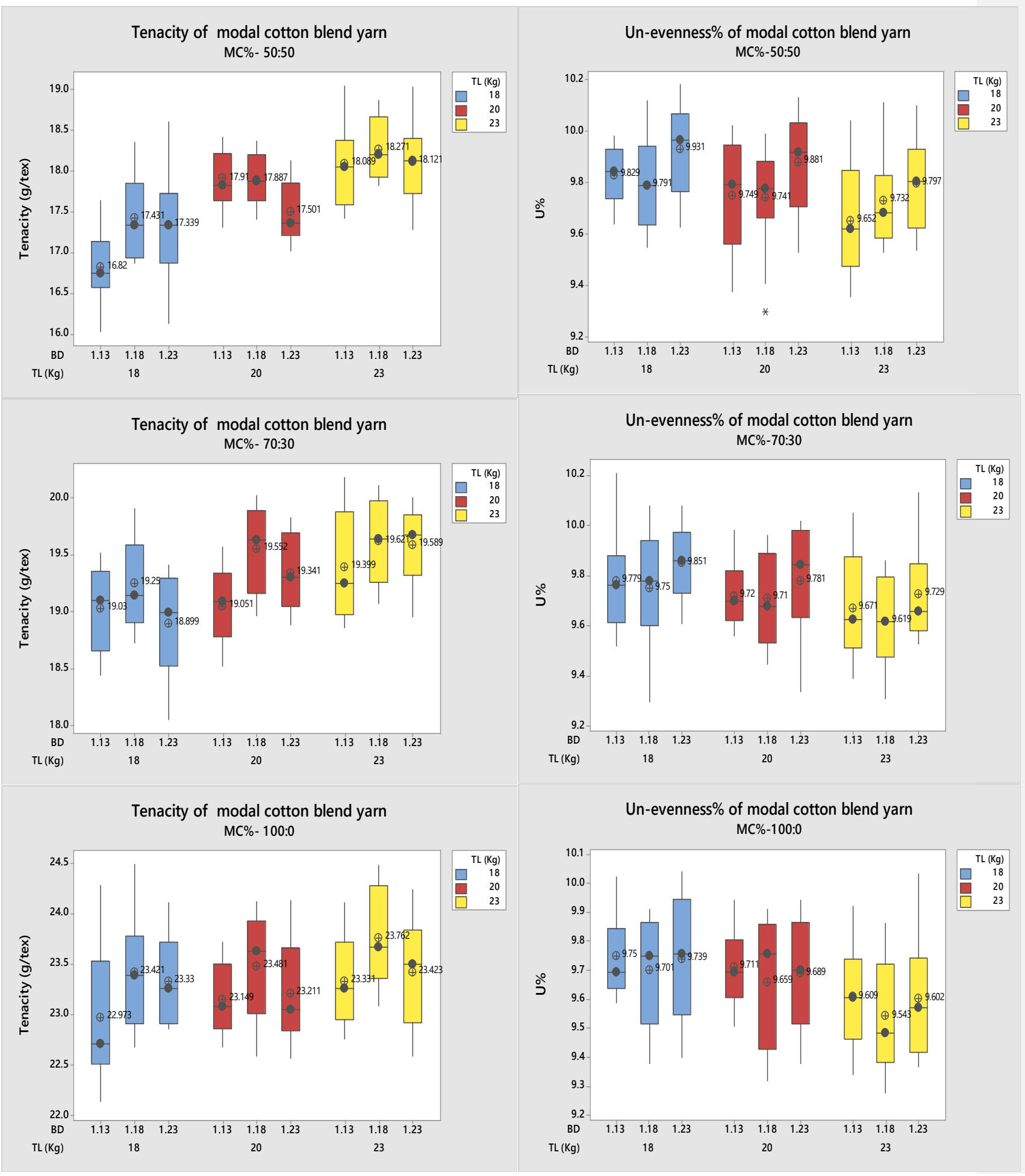

Figure 4. Effect of top roller loading and break draft on yarn tenacity and yarn $U \%$ 


\subsubsection{Unevenness (U\%)}

Analysis of Figure 4 reveals that the increase in top roller loading leads to decrease in unevenness of MC blend yarn. This may be due to the better consolidation and uniform movement of modal and cotton fibres during drafting at higher top roller loading. The blended yarn $\cup \%$ decreases initially and then increases as the break draft value increases. This may be due to the reason that the uniform movements of fibres are achieved in compact drafting system at the medium break draft level. It is observed that the minimum blended yarn $U \%$ is achieved at a top roller loading of $23 \mathrm{~kg}$, whilst minimum yarn $\mathrm{U} \%$ is obtained at a BD value of 1.18 in all the cases, except for 50:50 MC blend yarn produced at $23 \mathrm{~kg} \mathrm{TL}$, which shows better result at $1.13 \mathrm{BD}$.

Table 2. Parameters and their levels

\begin{tabular}{|c|c|c|c|c|}
\hline \multirow{2}{*}{ Factors } & \multirow{2}{*}{ Designation } & \multicolumn{3}{|c|}{ Levels } \\
\hline & & 1 & 2 & 3 \\
\hline Modal and Cotton blend ratio (MC \%) & A & $50: 50$ & $70: 30$ & $100: 0$ \\
\hline Top roller loading (TL) & B & Low $(18 \pm 0.5 \mathrm{~kg})$ & Medium $(20 \pm 0.5 \mathrm{~kg})$ & High $(23 \pm 0.5 \mathrm{~kg})$ \\
\hline Break draft (BD) & C & 1.13 & 1.18 & 1.23 \\
\hline
\end{tabular}

Table 3. Yarn properties and response values for $L_{9}$ array

\begin{tabular}{|c|c|c|c|c|c|c|c|c|c|}
\hline \multirow{2}{*}{$\begin{array}{c}\text { Experiment. } \\
\text { No. }\end{array}$} & \multicolumn{3}{|c|}{ Factors and levels } & \multirow{2}{*}{$\begin{array}{l}\text { Tenacity } \\
\text { (g/tex) }\end{array}$} & \multirow{2}{*}{$\begin{array}{c}\text { Unevenness } \\
(\%)\end{array}$} & \multirow{2}{*}{$\begin{array}{l}\text { Hairiness } \\
\text { Index }\end{array}$} & \multirow{2}{*}{$\begin{array}{l}\text { S/N for } \\
\text { tenacity }\end{array}$} & \multirow{2}{*}{$\begin{array}{c}\mathrm{S} / \mathrm{N} \text { for } \\
\text { unevenness }\end{array}$} & \multirow{2}{*}{$\begin{array}{c}S / N \text { for } \\
\text { hairiness } \\
\text { index }\end{array}$} \\
\hline & MC\% & $\mathrm{TL}$ & BD & & & & & & \\
\hline 1 & $50: 50$ & low & 1.13 & 16.82 & 9.83 & 5.33 & 24.5165 & -19.8511 & -13.4235 \\
\hline 2 & $50: 50$ & med & 1.18 & 17.89 & 9.74 & 4.96 & 25.0522 & -19.7712 & -12.2345 \\
\hline 3 & $50: 50$ & high & 1.23 & 18.12 & 9.80 & 4.63 & 25.1632 & -19.8245 & -12.0195 \\
\hline 4 & $70: 30$ & low & 1.18 & 19.25 & 9.75 & 4.64 & 25.6886 & -19.7801 & -11.8435 \\
\hline 5 & $70: 30$ & med & 1.23 & 19.34 & 9.78 & 4.11 & 25.7291 & -19.8068 & -11.7542 \\
\hline 6 & $70: 30$ & high & 1.13 & 19.40 & 9.67 & 4.04 & 25.7560 & -19.7085 & -12.1919 \\
\hline 7 & $100: 0$ & low & 1.23 & 23.33 & 9.74 & 3.86 & 27.3583 & -19.7712 & -14.4691 \\
\hline 8 & $100: 0$ & med & 1.13 & 23.15 & 9.71 & 4.05 & 27.2910 & -19.7444 & -14.2866 \\
\hline 9 & 100:0 & high & 1.18 & 23.76 & 9.54 & 3.69 & 27.5169 & -19.5910 & -13.0643 \\
\hline
\end{tabular}

Table 4. Response table for the mean $\mathrm{S} / \mathrm{N}$ ratio

\begin{tabular}{|c|c|c|c|c|c|}
\hline Parameters & Level 1 & Level 2 & Level 3 & Significance of parameters (Max-Min) & Rank \\
\hline \multicolumn{6}{|c|}{ Tenacity } \\
\hline $\mathrm{MC} \%$ & 24.91 & 25.72 & $27.39^{*}$ & 2.48 & 1 \\
\hline $\mathrm{TL}$ & 25.85 & 26.02 & $26.15^{*}$ & 0.29 & 2 \\
\hline BD & 25.85 & $26.09^{*}$ & 26.08 & 0.23 & 3 \\
\hline \multicolumn{6}{|c|}{ Unevenness } \\
\hline $\mathrm{MC} \%$ & -19.82 & -19.77 & $-19.70^{*}$ & 0.11 & 1 \\
\hline $\mathrm{TL}$ & -19.80 & -19.77 & $-19.71^{*}$ & 0.09 & 2 \\
\hline $\mathrm{BD}$ & -19.77 & $-19.71^{*}$ & -19.80 & 0.09 & 3 \\
\hline \multicolumn{6}{|c|}{ Hairiness index } \\
\hline $\mathrm{MC} \%$ & -12.56 & $-11.93^{*}$ & -13.94 & 2.01 & 1 \\
\hline $\mathrm{TL}$ & -13.25 & -12.76 & $-12.43^{*}$ & 0.82 & 3 \\
\hline $\mathrm{BD}$ & -13.30 & $-12.38^{*}$ & -12.75 & 0.92 & 2 \\
\hline
\end{tabular}

*Optimum level of parameters. 


\subsubsection{Hairiness index $(\mathrm{H})$}

It is observed from Figure 5 that the hairiness index of blended yarn decreases as the top roller loading increases in most of the cases because of the better consolidation of modal and cotton fibres during drafting at higher TL. With regard to break draft, no definite trend is obtained for the hairiness index of blended yarn samples. But it is found that better hairiness indexes are obtained at medium and higher break draft levels. This is because the preparation of modal and cotton fibres are better and may tend to work in to yarn well at this break draft levels. Here minimum hairiness index was obtained for the MC blend yarn at a top roller loading of $23 \mathrm{~kg}$, whilst better results are achieved for most of the blended yarn samples at 1.18 break draft and few others at 1.23 break draft.

\subsection{Parameter design optimisation by the Taquchi method}

The Taguchi parameter design analyses for the preparation of MC blend yarn with better yarn properties are reported. The levels of three parameters and their designations used for producing the yarn samples are given in Table 2.

\subsubsection{Analysis of $S / N$ ratio}

L9 orthogonal array showing nine experimental setup of blend yarn as well as the resulting yarn properties such as tenacity, unevenness and hairiness index along with the corresponding $\mathrm{S} / \mathrm{N}$ ratio values is reported in Table 3 . The average $\mathrm{S} / \mathrm{N}$ ratio values and their significance are given in Table 4 for the three yarn quality characteristics at all the three parameter levels.

The graphical representation of $\mathrm{S} / \mathrm{N}$ values showing main effects of all the three parameters are depicted in Figure 6 for the observed yarn properties. It is observed from Table 4 that the $\mathrm{MC}$ blend ratio is the most influential parameter amongst the three on all the three observed yarn properties.

By analysing Figure 6, the optimum parameter levels for achieving maximum yarn tenacity and minimum unevenness are found to be A3 B3 C2. The optimum parameter level for obtaining minimum hairiness index is observed to be $A 2 B 3 C 2$.

\subsubsection{ANOVA Analysis}

The results from the ANOVA analysis given in Table 5 reveal that the MC\% influences yarn tenacity values significantly $(97.26 \%)$ whilst the top roller loading $(1.3 \%)$ and break draft $(1.10 \%)$ influence tenacity value in a small level. Furthermore, the analysis shows that the influence of MC\% (41.45\%), top roller loading $(29.28 \%)$ and break draft $(24.57 \%)$ on the MC blended yarn unevenness are significant. Also the influence of $\mathrm{MC} \%$ on MC blend yarn hairiness index is maximum $(72.40 \%)$ followed by break draft (14.69\%) and top roller loading (11.65\%).

\subsubsection{Predicted optimum values and experimental values}

The predicted values of yarn quality characteristics calculated as per equation 5 and actual values obtained by producing

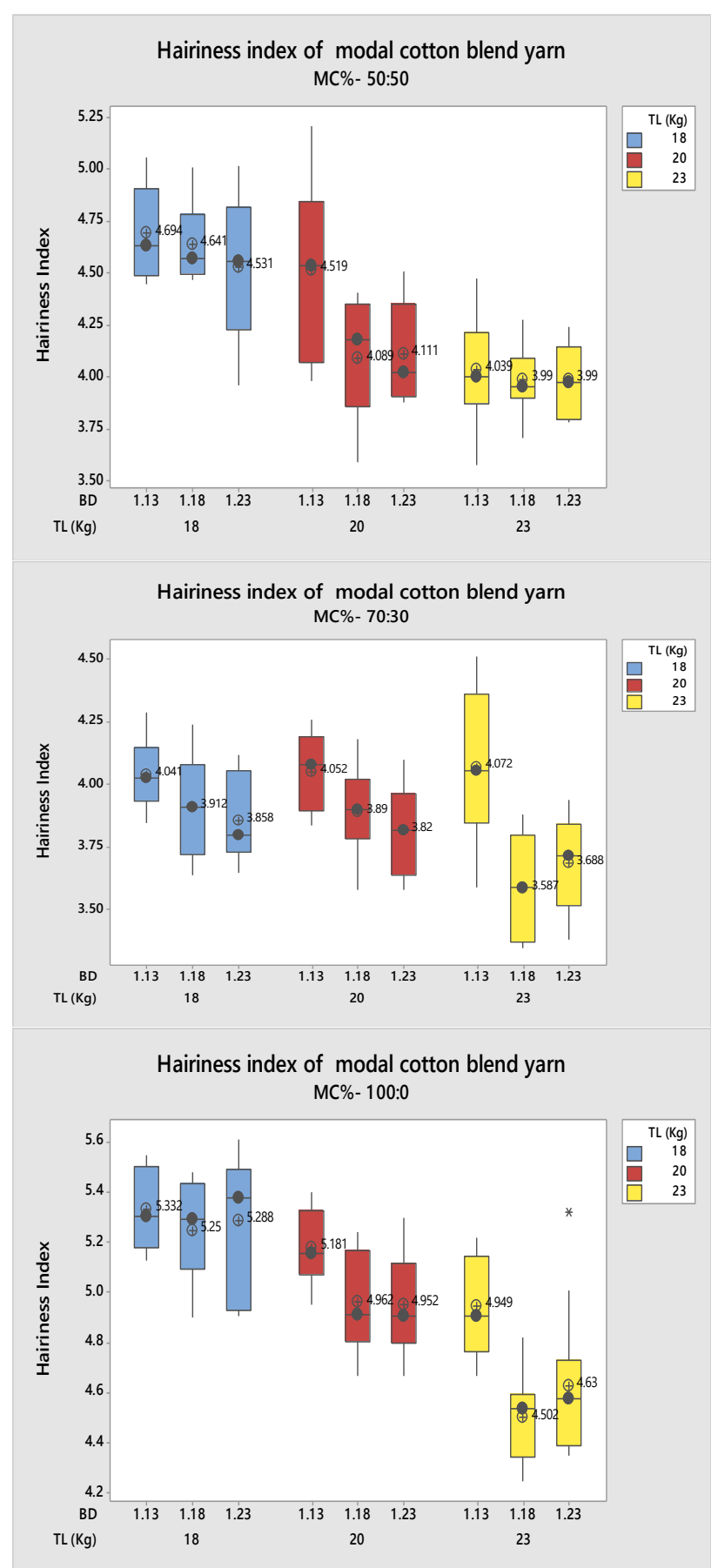

Figure 5. Effect of top roller loading and break draft on yarn hairiness index

yarn in optimum setting points are reported in Table 6 . It is observed that the predicted values of yarn properties are found to be very close to the actual values and fall within 95\% confidence interval. The improvement in optimum blended yarn properties compared to initial value for tenacity, unevenness and hairiness index are found to be $29.21 \%$, $3.15 \%$ and $48.46 \%$, respectively.

\section{Conclusions}

The effect of material parameter such as blend ratio of fibres (Cotton and Modal) and also ring spinning process 


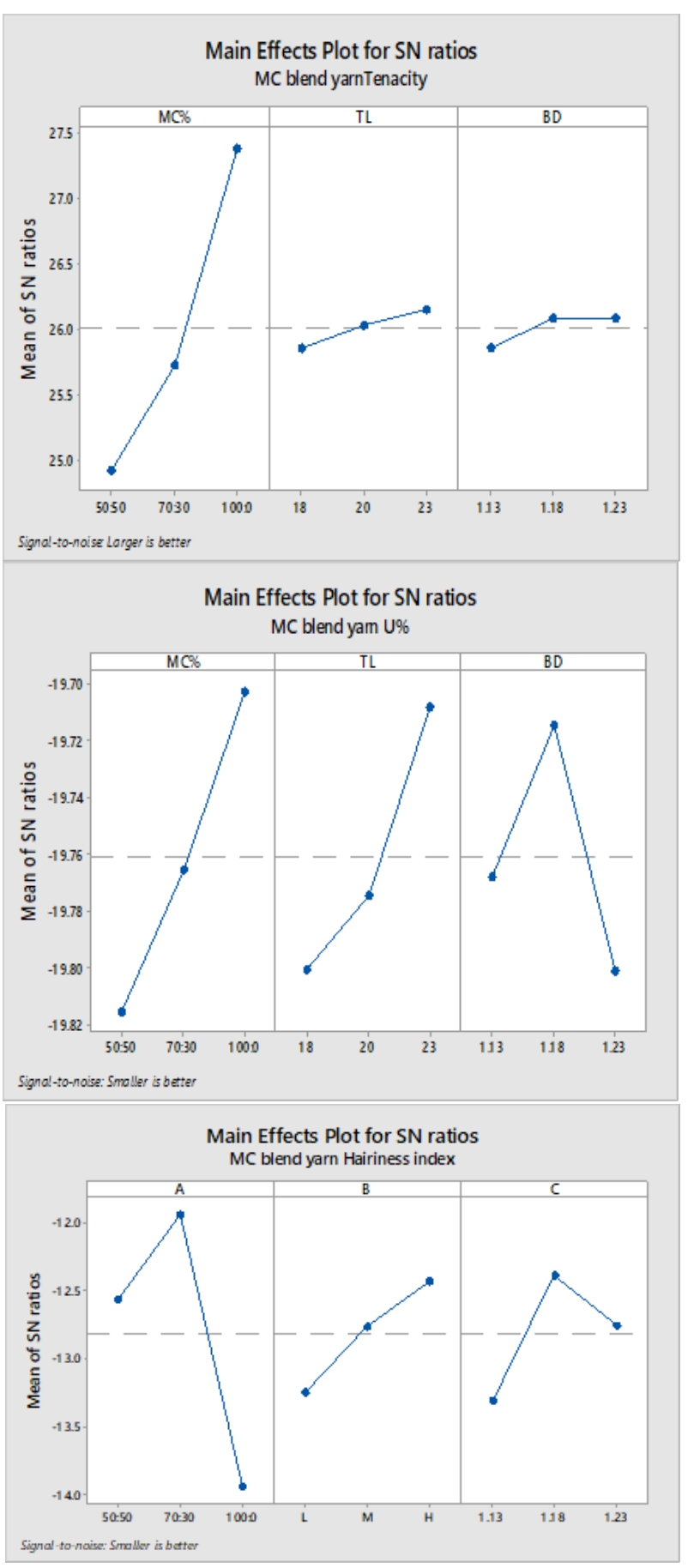

Figure 6. Mean S/N ratio plots: (a) Tenacity (b) $U \%$ and (c) hairiness index

parameters such as top roller loading and break draft on blended yarn quality characteristics were investigated in this study. The results indicated that the influence of MC blend ratio on all the three yarn properties were significantly higher, which was followed by that of top roller loading and break draft. Investigation of optimum parameters by the Taguchi analysis revealed that $100: 0 \mathrm{MC} \%, 23-\mathrm{kg}$ Top roller load and 1.18 break draft are found to be optimum setting values for producing the compact ring yarn with better tenacity and unevenness values. For producing compact ring yarn with better hairiness value, the optimum setting parameters are found to be $70: 30 \mathrm{MC} \%, 23 \mathrm{~kg}$ top roller load and 1.18 break draft. Also the optimal yarn properties obtained by conducting experiments at optimum settings is found to be well within $95 \%$ confidence interval of predicted values obtained using the Taguchi method. Moreover, a significant improvement in the optimum MC blended yarn properties is obtained compared to the yarn produced at initial setting values. In general, increase in the modal fibre proportion in blend ratio is found to yield better results in all the observed yarn characteristics except hairiness, which shows negative trend beyond 70:30 MC\%. With regard to top roller loading and break draft settings, desirable yarn characteristics are obtained at higher setting and moderate to higher settings, respectively.

\section{ACKNOWLEDGEMENT}

We thank the Management and Officials of Rajapalayam Mills Ltd., Rajapalayam, for permitted us to prepare and test of yarn samples in their organisation.

\section{References}

[1] Subramanian, N., Venkatachalam, A., Subramaniam, V (2007). Prediction and Optimization of Yarn Properties using Genetic Algorithm/Artificial Neural Network, Indian Journal of Fibre \& Textile Research, 32, 409-413.

[2] Sette, S, van Langenhove, L (2002). Optimising the fibre-toyarn production process: Finding a blend of fibre qualities to create an optimal Price/quality yarn, AUTEX Research Journal, Vol. 19, No 1, March 2019, 2(2), 57-63.

[3] Malik, S. A.; Tanwari, A., Syed, U., Qureshi, R. F.; \& Mengal, N. (2012). Blended Yarn Analysis: Part I-Influence of Blend Ratio and Break Draft on Mass Variation, Hairiness, and Physical Properties of 15 Tex PES/CO Blended Ring Spun Yarn. Journal of Natural Fibers, 9(3), 197-206.

[4] Samander Ali Malik, Assad Farooq, Thomas Gereke \& Chokri Cherif (2016). Prediction of Blended Yarn Evenness and Tensile properties by using Artificial Neural Network and Multiple Linear Regression, AUTEX Research Journal, Vol. 19, No 1, March 2019, 16(2), 43-50.

[5] Sekerden, $F$ (2011). Investigation on the Unevenness, Tenacity and Elongation Properties of Bamboo/Cotton Blended Yarns, Fibres \& Textiles in Eastern Europe,19(3), 26-29.

[6] Bhattacharya, S., S., Ajmeri, J. $R$ (2013). Investigation of Air Permeability of Cotton \& Modal Knitted Fabrics, International Journal of Engineering Research and Development, 6(12), 01-06.

[7] Gonca Balic Kilic, Ayse okur (2016). A Comparison of the Physical Properties of Cotton, Modal and Acrylic Yarns spun in Ring and OE-Rotor Spinning Systems, Industria Textila,67(2), 81-90.

[8] Majumdar, A., Das, A., Alagirusamy, R., Kothari, VK (Ed) (2013). Process control in Textile Manufacturing, Wood head publishing (Cambridge), 191.

[9] Ishtiaque, S. M., Rengasamy, R. S., Ghosh, A. (2004). Optimization Of Ring Frame Process Parameters For Better Yam Quality And Production, Indian Journal of Fibre \& Textile Research, 29(2), 190-195. 
Table 5. ANOVA results for $\mathrm{S} / \mathrm{N}$ ratio of yarn $\mathrm{T}, \mathrm{U} \%$ and $\mathrm{H}$

\begin{tabular}{|c|c|c|c|c|c|}
\hline Parameters & DF & Sum of square & Mean square & F-ratio & $\begin{array}{l}\text { Percentage } \\
\text { contribution }\end{array}$ \\
\hline \multicolumn{6}{|c|}{ Tenacity } \\
\hline $\mathrm{MC} \%$ & 2 & 9.5730 & 4.7865 & 279.45 & 97.26 \\
\hline $\mathrm{TL}$ & 2 & 0.1281 & 0.0641 & 3.74 & 1.30 \\
\hline BD & 2 & 0.1060 & 0.0530 & 3.09 & 1.10 \\
\hline Error & 2 & 0.0343 & 0.0171 & - & 0.34 \\
\hline Total & 8 & 9.8414 & - & - & 100.00 \\
\hline \multicolumn{6}{|c|}{ Unevenness } \\
\hline $\mathrm{MC} \%$ & 2 & 0.0194 & 0.0097 & 8.87 & 41.45 \\
\hline $\mathrm{TL}$ & 2 & 0.0137 & 0.0068 & 6.86 & 29.28 \\
\hline BD & 2 & 0.0115 & 0.0058 & 5.27 & 24.57 \\
\hline Error & 2 & 0.0022 & 0.0011 & - & 4.70 \\
\hline Total & 8 & 0.0468 & & & 100.00 \\
\hline \multicolumn{6}{|c|}{ Hairiness index } \\
\hline $\mathrm{MC} \%$ & 2 & 6.3432 & 3.1716 & 57.55 & 72.40 \\
\hline $\mathrm{TL}$ & 2 & 1.0208 & 0.5104 & 9.26 & 11.65 \\
\hline BD & 2 & 1.2866 & 0.6433 & 11.67 & 14.69 \\
\hline Error & 2 & 0.1102 & 0.0551 & - & 1.26 \\
\hline Total & 8 & 8.7609 & & & 100.00 \\
\hline
\end{tabular}

Table 6. Comparison of predicted and actual optimum yarn properties

\begin{tabular}{|c|c|c|c|c|c|}
\hline Yarn properties & $\begin{array}{l}\text { Optimum } \\
\text { Sequence }\end{array}$ & Predicted value & $\begin{array}{c}95 \% \text { Confidence } \\
\text { interval values }\end{array}$ & Actual value & $\begin{array}{l}\text { Improvement } \\
\text { in final yarn } \\
\text { property }(\%)\end{array}$ \\
\hline Tenacity & MC\%3 TL3 BD2 & $\begin{array}{l}23.99 \\
\text { g/tex }\end{array}$ & $\begin{array}{c}22.67 \leq 23.99 \leq \\
25.41\end{array}$ & $23.76 \mathrm{~g} / \mathrm{tex}$ & 29.21 \\
\hline Unevenness & MC\%3 TL3 BD2 & $9.55 \%$ & $9.42 \leq 9.55 \leq 9.69$ & $9.54 \%$ & 3.15 \\
\hline Hairiness index & MC\%3 TL3 BD3 & 3.51 & $2.62 \leq 3.51 \leq 4.40$ & 3.59 & 48.46 \\
\hline
\end{tabular}

[10] Ghane, M., Semnani, D., Saghafi, R. and Beigzadeh, H. (2008). Optimization of Top Roller Diameter of Ring Machine to Enhance Yarn Evenness by using Artificial Intelligence, Indian Journal of Fibre \& Textile Research, 33(1), 365-370.

[11] Khalilur Rahman Khan, Md., Ronobir Chandra Sarker, Mohammad Mahmudur Rahman Khan. (2014). Interactive Effect of Blend Proportion and Process Parameters on Ring Spun Yarn Properties and Fabric GSM Using Box and Behnken Experimental Design, International Journal of Engineering Research and Technology, 3(11), 1609-1613.

[12] Arindam Basu,. Rajanna Gotipamul (2005). Effect of Some Ring Spinning and Winding Parameters on Extra Sensitive Yarn Imperfections, Indian Journal of Fibre \& Textile Research, 30, 211-214.

[13] Mohammad Hatamvand, Seyed Abbas Mirjalili, Saeid Fattahi, Tariq Bashir, Mikael Skrifvars (2017). Optimum Drafting Conditions of Polyester and Viscose Blend Yarns, AUTEX Research Journal, Vol. 19, No 1, March 2019, 17 (3), 213-218.
[14] Khalilur Rahman Khan, Md., Mohammad Mobarak Hossain, Ronobir Chandra Sarker (2015). Statistical Analyses and Predicting the Properties of Cotton/Waste Blended Open-End Rotor Yarn using Taguchi OA Design, International Journal of Tex Science, 4(2), 27-35.

[15] Taguchi, G., Chowdhury, S., Wu, Y. (2004). Taguchi's Quality Engineering handbook, John Wiley \& sons, Inc., New jersey, 501.

[16] Akshay Kumar, Ishtiaque, S. M. and Salhotra, K. R. (2006). Study of effect of spinning process variables on the packing density of ring, rotor and air-jet yarns using the Taguchi method, AUTEX Research Journal, Vol. 19, No 1, March 2019, 6(3), 122-135.

[17] Akshay Kumar, Ishtiaque, S. M. and Salhotra, K. R. (2006). Analysis of Spinning Process Using Taguchi Method Part IV: Effect of Spinning Process Variables on Tensile Properties of Ring, Rotor and Air-Jet Yarns, Journal of Text Institute, 97(5), 385-390. 
[18] Akshay Kumar, Ishtiaque, S. M. and Salhotra, K. R. (2006). Analysis of Spinning Process Using Taguchi Method Part V: Effect of Spinning Process Variables on Physical Properties of Ring, Rotor And Air-Jet Yarns, Journal of Text Institute, 97(6), 463-473.

[19] Serin Mavruz, Tugrul Ogulata, R.(2010). Taguchi Approach for the Optimization of the Bursting Strength of Knitted Fabrics, Fibres \& Textiles in Eastern Europe, 18(2), 78-83.

[20] Tanveer Hussain , Farooq Ahmed Arain , Zulfiqar Ali Malik (2017). Use Of Taguchi Method And Grey Relational Analysis To Optimize Multiple Yarn Characteristics In Open-End Rotor Spinning, AUTEX Research Journal, Vol. 19, No 1, March 2019, 17(1), 67-72.
[21] Anindya Ghosh, Prithwiraj Mal, Abhijit Majumdar, and Debamalya Banerjee (2017). An Investigation on Air and Thermal Transmission through Knitted Fabric Structures using the Taguchi Method, AUTEX Research Journal, Vol. 19, No 1, March 2019, 17(2), 152-163. 